\title{
Práticas de cuidado no puerpério desenvolvidas por enfermeiras em Estratégias
}

\section{de Saúde da Família}

Puerperal care practices developed by nurses in the Family Health Strategies

Prácticas de cuidado en el puerperio desarrolladas por las enfermeras en las Estrategias de Salud

Familiar

\begin{abstract}
Críslen Malavolta Castiglioni ${ }^{\mathrm{I}}$, Luiza Cremonese ${ }^{\mathrm{II}}$, Lisie Alende Prates ${ }^{\mathrm{II}}$, Maria Denise Schimithiv, Graciela Dutra Sehnemv ${ }^{\text {, Laís Antunes Wilhelm }}{ }^{\mathrm{I}}$
\end{abstract}

\begin{abstract}
Resumo: Objetivo: conhecer as práticas de cuidado desenvolvidas por enfermeiras de Estratégias de Saúde da Família para mulheres no puerpério. Método: pesquisa qualitativa realizada entre dezembro de 2016 e janeiro de 2017 por meio de entrevista semiestruturada com nove enfermeiras. Os dados foram analisados conforme a proposta operativa. Resultados: as consultas puerperais acontecem em torno de uma a duas vezes dentro de 30 dias e são realizadas, majoritariamente, pelas enfermeiras por meio do exame físico obstétrico, cuidados com a incisão da cesariana ou episiotomia, avaliação de aspectos emocionais e orientações sobre sexualidade, planejamento reprodutivo, amamentação, cuidados com o recém-nascido e vínculo entre mãe e bebê. Conclusão: as enfermeiras percebem a relevância das práticas do cuidado e suas principais características, pois reconhecem as alterações hormonais, emocionais e sociais do período e a importância da atuação de profissionais nessa fase cercada por transformações, adaptações e vulnerabilidade.

Descritores: Período Pós-Parto; Estratégia Saúde da Família; Cuidado Pós-Natal; Cuidados de Enfermagem; Enfermagem
\end{abstract}

\footnotetext{
IEnfermeira Obstetra, Mestre em Enfermagem pelo Programa de Pós-Graduação em Enfermagem da Universidade Federal de Santa Maria (PPGEnf/UFSM). Santiago, RS, Brasil. E-mail: crislen_castiglioni@hotmail.com. ORCID: https://orcid.org/0000-0002-6984-4557

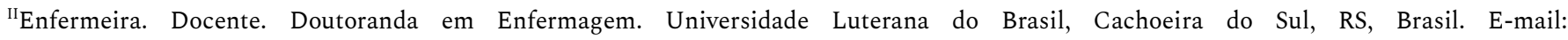
lu_cremonese@hotmail.com. ORCID: https://orcid.org/0000-0001-7169-1644

IIIEnfermeira. Docente. Doutora em Enfermagem. Universidade Federal do Pampa, Uruguaiana, RS, Brasil. E-mail: lisiealende@hotmail.com. ORCID: https://orcid.org/0000-0002-5151-0292

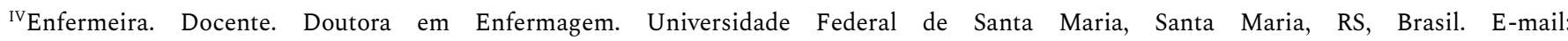
ma.denise2011@gmail.com. ORCID: http://orcid.org/0000-0002-4867-4990

v Enfermeira. Docente. Doutora em Enfermagem. Universidade Federal de Santa Maria, Santa Maria, RS, Brasil. E-mail: graci_dutra@yahoo.com.br. ORCID: https://orcid.org/0000-0003-4536-824X

VI Enfermeira. Docente. Doutora em Enfermagem. Universidade Federal de Santa Catarina, Florianópolis, SC, Brasil, E-mail: lais.wilhelm@ufsc.br. ORCID: https://orcid.org/0000-0001-6708-821X
} 


\begin{abstract}
Objective: to know the care practices developed by nurses from the Family Health Strategies for women in the puerperium. Method: qualitative research conducted between December 2016 and January 2017 through interviews with nine nurses. The data were analyzed according to the operative proposal. Results: The puerperal appointments occur around one to two times within 30 days and are performed mostly by nurses through obstetric physical examination, care with the cesarean or episiotomy incision, evaluation of emotional aspects and guidelines on sexuality, reproductive planning, breastfeeding, newborn care and the bond between mother and baby. Conclusion: the nurses perceive the relevance of the care practices and their main characteristics, because they recognize the hormonal, emotional and social changes of the period and the importance of the work of professionals in this stage surrounded by changes, adaptations and vulnerability.
\end{abstract}

Descriptors: Postpartum Period; Family Health Strategy; Postnatal Care; Nursing Care; Nursing

Resumen: Objetivo: conocer las prácticas de atención desarrolladas por enfermeras de Estrategias de Salud Familiar a las mujeres en el puerperio. Método: investigación cualitativa realizada entre diciembre de 2016 y enero de 2017 mediante entrevistas con nueve enfermeras. Se analizaron los datos de acuerdo con la propuesta operativa. Resultados: las consultas puerperales ocurren alrededor de una a dos veces en un plazo de 30 días y son ejecutadas principalmente por enfermeras a través de un examen físico obstétrico, cuidados con la incisión de la cesárea o episiotomía, evaluación de aspectos emocionales y directrices sobre la sexualidad, la planificación reproductiva, lactancia materna, neonatal y el vínculo entre la madre y el bebé. Conclusión: las enfermeras perciben la relevancia de las prácticas de atención y sus características principales, ya que reconocen los cambios hormonales, emocionales y sociales del periodo y la importancia de la actuación de los profesionales en este escenario, rodeado por los cambios, adaptaciones y vulnerabilidad.

Descriptores: Período Posparto; Estrategia de Salud Familiar; Atención Posnatal; Atención de Enfermería; Enfermería

\title{
Introdução
}

O puerpério é o período do ciclo gravídico-puerperal que corresponde à regressão física gravídica e à passagem para o exercício da maternidade. Ele inicia logo após a dequitação da placenta e termina por volta de seis semanas após o parto, período marcado por diversas mudanças corporais e adaptações emocionais, que podem resultar em desafios que comprometem a relação mãe-filho. ${ }^{1-2}$

No puerpério, mulheres, recém-nascidos $(\mathrm{RN})$ e famílias apresentam necessidades de saúde. Apesar de se esperar que seja um período de vivências saudáveis, podem surgir problemas de ordem física, subjetiva, relacional e social. ${ }^{3}$ As profundas transformações 
3 | Castiglioni CM, Cremonese L, Prates LA, Schimith MD, Sehnem GD, Wilhelm LA

vivenciadas nesse ciclo podem expor as mulheres a agravos específicos de morbimortalidade materna..$^{2-4}$

Assim, as puérperas merecem atenção especial dos serviços e profissionais de saúde, os quais precisam estar comprometidos na avaliação e no cuidado dispensado à mulher, ao RN e à família. ${ }^{5}$ Essa fase é cercada por experiências únicas, e as práticas de cuidado desenvolvidas pelos profissionais de saúde precisam contemplar ações voltadas ao RN e à puérpera, a qual necessita ser avaliada quanto à presença e à gravidade de alterações físicas e emocionais. ${ }^{6-7}$

Os profissionais de saúde integrantes das equipes de atenção primária à saúde (APS) precisam estar capacitados para acolher precocemente a puérpera e a família, a fim de prevenir o surgimento de problemas e dificuldades relacionados à vivência desse período. ${ }^{8}$ As práticas de cuidado, no âmbito das Estratégias Saúde da Família (ESF), precisam incluir, além do acolhimento: vinculação da mulher, do homem e da família ao serviço local; atenção clínicoeducativa de acompanhamento das mudanças orgânicas da mulher; ações de planejamento reprodutivo, de prevenção do câncer de mama, do câncer de colo uterino e das infecções sexualmente transmissíveis; apoio continuado à amamentação e ao cuidado do RN; auxílio psicoemocional à maternidade e paternidade; informação e educação voltadas à saúde no pósparto; atividades sociais de promoção da saúde reprodutiva. ${ }^{9}$

As práticas de cuidado à mulher no pós-parto, na rede de APS, não têm sido efetivadas. ${ }^{10}$ No entanto, segundo recomendações do Ministério da Saúde (MS), a sua implementação é importante para que ocorra o desenvolvimento de ações educativas e preventivas, detecção precoce de situações de risco puerperal, estabelecimento de vínculo entre o hospital e as ESF e operacionalização do acesso da puérpera e RN a serviços de saúde de qualidade. ${ }^{9}$

No panorama brasileiro, as ações são consideradas insatisfatórias, entre outras razões, devido a problemas na organização da rede de serviços, na educação e promoção da saúde, no vínculo entre as mulheres e a equipe de saúde da ESF e ao fato das práticas de cuidado dos 
Práticas de cuidado no puerpério desenvolvidas por enfermeiras em Estratégias de... |4

profissionais estarem voltadas às necessidades da criança. ${ }^{3}$ As experiências reprodutivas e da maternidade, comumente, resultam em novas condições de existência para as famílias, tanto em mudanças pessoais e relacionais quanto em adaptações que precisam ser consideradas pelo serviço de saúde. ${ }^{2}$

Desde essa perspectiva, nas ESF, a consulta de puerpério e a visita domiciliar (VD) não têm se constituído em espaços para acolher as angústias, receios, desejos e necessidades das mulheres. ${ }^{3-11}$ Ao que se refere à consulta puerperal, apesar de constituir uma das ações previstas no cuidado à saúde da mulher, são baixas a frequência das consultas na APS e, quando ocorrem, voltam-se meramente à questão da anticoncepção. ${ }^{3}$ Dentre as razões para a baixa frequência de consultas puerperais, autores na área citam a ausência desse atendimento no serviço de saúde, falta de agendamento da consulta específica para puérperas, desorganização no agendamento, perda de prontuários, dificuldade das usuárias em obter informações e resistência das mulheres em realizar a consulta com o enfermeiro, exigindo a presença ou a realização do atendimento por um médico. ${ }^{3}$

Quanto à VD, embora sua realização seja imprescindível no puerpério para avaliar as condições de saúde da mãe e do RN, bem como fornecer orientações de promoção da saúde e identificar agravos e intercorrências para a adoção de condutas, ${ }^{3}$ seu planejamento é inexistente, como apontam os estudos na APS.,11 Dessa forma, muitas vezes, os profissionais das ESF não realizam a VD e aguardam a puérpera direcionar-se à unidade para realizar a consulta ou delegam a atividade ao agente comunitário de saúde (ACS). ${ }^{3}$

Vislumbra-se pouca disponibilidade e efetivação de práticas de cuidado na atenção puerperal, o que desvaloriza o período enquanto qualificador do cuidado e promotor de saúde. A visibilidade dessa problemática enseja a produção de espaços privilegiados de escuta na relação entre profissionais, puérperas e famílias, sinalizando para a urgência de investimentos no componente relacional do cuidado. 
5 | Castiglioni CM, Cremonese L, Prates LA, Schimith MD, Sehnem GD, Wilhelm LA

Mediante o exposto, a questão de pesquisa que orienta este trabalho apresenta-se da seguinte maneira: quais as práticas de cuidado desenvolvidas no período puerperal por enfermeiras em Estratégia de Saúde da Família (ESF)? Para responder a questão, objetiva-se conhecer as práticas de cuidado desenvolvidas por enfermeiras de Estratégias de Saúde da Família para as mulheres no puerpério.

\section{Método}

Trata-se de um estudo de abordagem qualitativa, de campo e de caráter descritivo, realizado em ESF de um município do interior do Rio Grande do Sul. A APS local é composta por 32 serviços de saúde, sendo 11 ESF urbanas, três dessas unidades de saúde contam com duas equipes de ESF e duas estão localizadas em zonas rurais, além de 19 Unidades Básicas de Saúde (UBS), resultando em uma cobertura de ESF em torno de $22 \%$. As nove equipes simples contam com uma enfermeira por unidade, enquanto as três equipes duplas possuem duas enfermeiras por unidade, totalizando 14 profissionais distribuídas nos 11 serviços. Ressalta-se ainda que o município é dividido em oito regiões de saúde e uma Unidade distrital.

O cenário do estudo contemplou todas as regiões de saúde do município que contavam com ESF. Justifica-se a escolha desse cenário para a realização da pesquisa devido à recomendação da realização de consultas puerperais pelo MS. ${ }^{9}$

O encerramento da pesquisa aconteceu frente ao alcance do objetivo e, também, quando já não foram identificadas contribuições diferentes daquelas encontradas no decorrer das entrevistas. ${ }^{12}$ Cabe destacar, ainda, que a análise ocorreu concomitante à coleta de dados, o que possibilitou considerar o critério de saturação de dados. ${ }^{12}$

Participaram da pesquisa nove enfermeiras de sete ESF da zona urbana do município estudado, das quais duas são unidades de saúde com duas equipes de ESF. Os critérios estabelecidos para seleção foram: trabalhar nas ESF da zona urbana do município e apresentar 
Práticas de cuidado no puerpério desenvolvidas por enfermeiras em Estratégias de... |6

tempo de atuação no serviço superior a seis meses. Quanto ao último critério, esperava-se que o profissional apresentasse adaptação ao serviço e conhecimento acerca da realidade da comunidade.

Os dados foram coletados entre dezembro de 2016 e janeiro de 2017 por meio de uma entrevista semiestruturada, tendo em média 45 minutos cada. Estavam presentes somente a pesquisadora e a participante, com o intuito de promover aproximação e fluidez.

O roteiro apresentava as seguintes perguntas: Você realiza consultas de pré-natal? Como você orienta o retorno da mulher à unidade de saúde após o parto para consulta de puerpério? Conte-me como costumam acontecer as consultas de puerpério? Como você procede no caso de puérperas faltantes às consultas? O que você considera mais importante no cuidado no puerpério? Fale-me acerca da rede cegonha e sua prática em relação a isso. O que você sabe acerca do puerpério de maneira geral?

Anterior ao início da coleta de dados, foi realizado contato telefônico com as enfermeiras das ESF para apresentação do projeto e questionamento acerca do interesse em participar da pesquisa. Nesse momento, agendou-se um dia nos serviços de saúde, após o turno de trabalho, de acordo com a disponibilidade das participantes, para esclarecimentos e realização das entrevistas, as quais foram gravadas após o aceite e autorização, por meio do Termo de Consentimento Livre e Esclarecido. Posteriormente, as gravações foram transcritas, analisadas e interpretadas conforme a proposta operativa. ${ }^{12}$ Para isso, realizou-se uma pré-análise com leitura flutuante, grifou-se os dados coletados em colorido e, então, explorou-se o material de análise, organizando-os em categorias.

O comprometimento com o sigilo e anonimato foi garantido pela assinatura do Termo de Confidencialidade pela pesquisadora e sua orientadora e pela utilização da letra "E" (representando enfermeiras) somada à numeração pela ordem das entrevistas (E1, E2, E3...) para identificação das participantes no estudo. A pesquisa foi aprovada no dia 15 de dezembro de 
7 | Castiglioni CM, Cremonese L, Prates LA, Schimith MD, Sehnem GD, Wilhelm LA

2016 pelo Comitê de Ética da Universidade Federal de Santa Maria, sob o número de parecer 1.867.430, CAAE 62063216.9.0000.5346, e respeitou durante o percurso os preceitos éticos previstos na resolução nº 466, de 12 de dezembro de 2012.

\section{Resultados e discussão}

As enfermeiras visualizavam o puerpério como um período marcado por mudanças fisiológicas, emocionais e sociais, que demarcam um “renascimento" feminino. Também o simbolizaram como uma fase de transformação, adaptação e vulnerabilidade, que demanda sensibilidade do profissional de saúde.

Eu acho que é um período de adaptação. Se eu tivesse que colocar, assim, em uma palavra: adaptação. Adaptação de todo mundo, da família com a criança, da criança com o mundo sabe, e precisa de muita assistência. (E1)

É uma mudança de vida brusca. É uma coisa que mexe com muitos sentimentos, emoções e isso influencia o estado emocional [...] é um período de adaptação de processos, muda tudo, na cabeça, no pensamento, na vida, bagunça tudo. Transformação e adaptação, principalmente para quem é primigesta. (E2)

Acho que o puerpério é um período de renascimento para mulher, que é tudo novo para elas [...] tem alterações hormonais, fisiológicas, é um período que a gente também ter que ter uma sensibilidade de compreender o que elas estão passando e as dificuldades que estão vivenciando. (E4)

Por meio dos relatos, foi possível compreender que as enfermeiras entendem as transformações advindas do puerpério e reconhecem a importância das práticas de cuidado à mulher nessa fase. Para elas, nesse momento, as mulheres ficam mais sensibilizadas e vulneráveis, vivenciando uma nova etapa da vida, permeada por dúvidas, que podem implicar em alterações emocionais, principalmente, quando primigestas. 
Práticas de cuidado no puerpério desenvolvidas por enfermeiras em Estratégias de... $\mid 8$

Torna-se fundamental que as enfermeiras compreendam o puerpério como um momento de fragilidade, no qual os cuidados com o $\mathrm{RN}$, os reajustes familiares e o próprio autocuidado podem gerar insegurança, ansiedade e dúvidas nas mulheres. ${ }^{5}$ Ao reconhecer que esse período, normalmente, é cercado de incertezas, independente de ser ou não a primeira experiência, os profissionais de saúde podem priorizar as necessidades individuais de cada puérpera ${ }^{13}$ e desenvolver práticas de cuidado, que ultrapassem os aspectos físicos, abrangendo também questões emocionais e relacionais, permitindo, assim, que a mulher o vivencie com segurança e plenitude.

Ademais, as práticas de cuidado no período puerperal carecem de uma relação humanizada, com escuta ativa e sensível e com o estabelecimento de vínculos entre profissionais de saúde, familiares e puérperas, priorizando que sejam as verdadeiras protagonistas no processo decisório de seu cuidado. ${ }^{14}$ A vivência saudável do puerpério precisa ser contemplada na atuação dos profissionais, e o bem-estar e a minimização da morbidade e mortalidade materna e neonatal necessita ser uma das prioridades de suas práticas de cuidado. ${ }^{13}$ Ressalta-se que o enfermeiro apresenta um papel e, nesse sentido, o cuidado precisa compreender a puérpera de forma multidimensional e atender suas necessidades de saúde.

No que diz respeito ao cuidado no puerpério nas ESF, as participantes mencionaram como ocorrem os agendamentos na APS, além da periodicidade e o número de consultas nessa fase. Uma delas ainda afirma que a consulta puerperal acontece de forma concomitante à puericultura ou ao teste do pezinho.

Ah, em seguida, depois do parto a gente já marca, não deixa passar muito tempo, mas agora não vou saber te dizer exatamente quantos dias, mas até os trinta dias ela já vai ter consultado. (E3)

No puerpério, a gente faz uma só [...] a gente não costuma agendar duas consultas puerperais. A gente tenta na primeira semana, mas no máximo até duas semanas. (E6) 
9 | Castiglioni CM, Cremonese L, Prates LA, Schimith MD, Sehnem GD, Wilhelm LA

Em média duas, porque, na verdade, já é a da criança junto. A gente já faz a primeira consulta de puerpério no teste do pezinho e com trinta dias. (E7)

As respostas variaram entre uma e duas consultas, e o momento em que foram realizadas ficou em torno dos 30 dias, principalmente no retorno da mulher à unidade para a realização do teste do pezinho.

Diante do exposto, percebe-se que o cuidado no puerpério tem recebido atenção e vem acontecendo, em algum momento, nas unidades, sendo, por vezes, como recomenda o MS, que preconiza duas consultas. A primeira precisa acontecer até o sétimo ou décimo dia após a alta hospitalar por meio de uma VD ou na própria unidade e a segunda até 42 dias, agendada como um retorno da puérpera ao serviço de saúde. ${ }^{9}$

Os achados aqui contemplados podem ser vistos, consideravelmente, como positivos se comparados a uma pesquisa ${ }^{15}$ desenvolvida na Bahia com 17 puérperas cadastradas em uma ESF, em que a maioria das puérperas não realizou a consulta de puerpério dentro dos 30 dias. Ainda, pesquisa $^{3}$ realizada no Recife, em 2017, aponta que o cuidado no puerpério ocorreu por meio de VD. No entanto, as práticas de cuidado à puérpera foram ofertadas apenas uma vez e por ACS.

A consulta puerperal é um direito de todas as mulheres no pós-parto, e cabe aos profissionais de saúde, em especial aos de enfermagem, responsáveis pelo cuidado direto e integral da puérpera, ${ }^{16-17}$ refletirem acerca das práticas de cuidado a essa clientela, procurando garantir a promoção da saúde e bem-estar. ${ }^{17}$ Nesse sentido, de acordo com estudo realizado com enfermeiros de ESF, ações relacionadas a capacitações da equipe, educação continuada e permanente e organização de protocolos para a assistência ao puerpério são estratégias que podem contribuir para a qualificação do cuidado durante o período puerperal. ${ }^{1}$

Além disso, ressalta-se que tanto o enfermeiro quanto o médico estão aptos para o desenvolvimento da consulta puerperal. Entretanto, nos serviços de saúde das participantes deste estudo, verificou-se algumas variações na organização e realização desse atendimento. 
Práticas de cuidado no puerpério desenvolvidas por enfermeiras em Estratégias de... | 10

Geralmente, é a enfermagem responsável pela realização da consulta puerperal. Quando tem alguma necessidade a gente passa para o médico. (E3)

Normalmente nós. Nós temos a pediatra do NASF, que ela faz as Inter consultas com a gente da puericultura, então elas auxiliam a gente, por exemplo, se agente marca o retorno de 30 dias, aí a pediatra está junto na consulta, consulta de enfermagem com a pediatra.(E4)

Nós duas também [médica e enfermeira]! Tanto eu como ela pode fazer a primeira consulta. (E8)

A consulta é ele que faz [médico], porque ele teve disponibilidade de horário, pela demanda, mas, no geral, outras dúvidas, geralmente, é com o enfermeiro. (E9)

Conforme os depoimentos, as consultas são realizadas, predominantemente, pelas enfermeiras, mas também aparecem como sendo de responsabilidade dos médicos, ou ainda intercaladas pelos dois profissionais. Ressalta-se que, mesmo quando são os médicos que realizam as consultas de puerpério, as enfermeiras ainda são referência para esclarecer as dúvidas das mulheres.

O predomínio da atuação de enfermeiros no desenvolvimento das consultas puerperais também foi encontrado em estudo ${ }^{3}$ realizado em uma ESF de Recife, no ano de 2017, que buscou compreender as percepções e práticas relativas ao acolhimento no cuidado puerperal à mulher. Ao que se refere ao atendimento multidisciplinar no puerpério, vale enfatizar que a consulta médica não substitui a de enfermagem, pois as duas se complementam e ambas desempenham papel fundamental no cuidado. ${ }^{3}$

As práticas de cuidado à saúde da mulher, em todas as fases da vida, precisam ser uma das prioridades de todos os profissionais que atuam em ESF. Diante disso, a equipe de saúde, nos serviços, precisa compreender a importância de um cuidado puerperal de qualidade, que aconteça de forma integral, ultrapassando os limites dos procedimentos técnicos e proporcionando escuta qualificada e atenção às necessidades biopsicossociais da puérpera. ${ }^{18} \mathrm{O}$ 
11 | Castiglioni CM, Cremonese L, Prates LA, Schimith MD, Sehnem GD, Wilhelm LA

suporte no puerpério é algo essencial e quando acontece de maneira adequada, direcionado ao binômio mãe-bebê, com a oportunidade da manifestação dos anseios e queixas maternas, bem como de esclarecimento de seus questionamentos, promove a satisfação das puérperas, uma vez que ter o apoio de alguém que sane as suas dúvidas e transmita autoconfiança é indispensável para o seu desempenho materno e a vivência do período sem complicações. ${ }^{18-19}$

Ressalta-se que o enfermeiro apresenta papel importante no cuidado do puerpério no que se refere à realização da consulta puerperal de enfermagem, ação que possibilita orientações, intervenções e ações de prevenção e cuidado que minimizam riscos e contribuem para o bem estar materno e infantil. ${ }^{1}$ Nesse sentido, como peça fundamental das práticas de cuidado à puérpera na APS ${ }^{16,19}$ esses profissionais precisam prestar assistência de modo a contribuir de maneira significativa para a redução dos índices de mortalidade materna e perinatal. Dentre suas ações importantes, é possível destacar o fornecimento de orientações sobre o autocuidado e a avaliação do estado psicológico materno, cuidados com o RN e acolhimento e esclarecimento de angústias, receios, desejos e necessidades individuais de cada mulher. ${ }^{1-6}$

Nessa perspectiva, as enfermeiras relataram as informações abordadas durante a consulta puerperal. Observa-se que as orientações partem do nascimento do RN até o momento atual da consulta.

Quando foi o parto, qual o tipo de parto, se teve alguma intercorrência, se fez alguma medicação, quando deu alta, quanto tempo ficou de parto, se foi rápido ou demorado, se foi direto para cesárea, se foi induzido. $A$ questão do aleitamento, normalmente, a gente pede para mãe dar mamá na frente da gente, porque a gente consegue ver. Quem é que cuida do bebê, se tem alguém para ajudar, a questão de dor nos pontos, se é cesárea ou episio, como é que está o cuidado. Orientação da livre demanda do aleitamento, alimentação. A adaptação da vida da mulher em continuar sendo mulher. A relação dos irmãos [com o bebê], se tem irmão mais velho, a questão de não abandonar os outros irmãozinhos e ver como é que eles estão reagindo [em relação ao bebê] para tentar estimular essa questão do vínculo familiar. E vacinas também da mãe. (E1) 
Práticas de cuidado no puerpério desenvolvidas por enfermeiras em Estratégias de... | 12

[...] quando é cesariana a gente avalia a cicatriz pós-operatória, conversa com ela para tentar ver como está a amamentação, faz o bebê mamar na hora para ver como é que está a pega, vê se ela está bem, como é que estão os lóquios, para ver se está tudo normal. Avalia ela e o bebê, avalia peso, pressão arterial, conversa para ver como é que ela está se sentindo, métodos anticoncepcionais [...]. (E2)

A atividade sexual, o uso do contraceptivo, a amamentação, alimentação, hidratação e o controle da perda. (E5)

De acordo com os depoimentos das participantes, elas costumam abordar as questões preconizadas pelo MS durante o atendimento à puérpera. No entanto, algumas relataram as práticas de cuidado de modo mais completo, enquanto outras foram objetivas. Os cuidados que mais apareceram foram em relação ao tipo de parto, observação dos lóquios, involução uterina, sinais de infecção, como dor e febre, cuidados com a incisão da cesariana ou episiotomia, verificação da pressão arterial, amamentação, alimentação, higiene, atividade sexual, métodos contraceptivos, planejamento familiar, apoio social para cuidar do bebê, sentimentos manifestados pela puérpera, depressão pós-parto e cuidados com o RN. Além dessas, as participantes também citaram as orientações que englobavam o trabalho de parto, hidratação, contato da mãe com o bebê, relação dos irmãos com o novo membro, vínculo familiar e as dúvidas das próprias puérperas.

Diante do exposto, ressalta-se que os achados do estudo apresentam resultados positivos e importantes, uma vez que, no Brasil, a assistência puerperal além de acontecer apenas no período logo após o parto, ela é, muitas vezes, limitada e direcionada a questões do cuidado da criança, com foco no aleitamento materno. ${ }^{6} \mathrm{O}$ puerpério pode ser vivenciado sem intercorrências ou ainda com problemas significativos que podem se estender por semanas, meses ou anos. Nesse sentido, precisa receber atenção e cuidado longitudinal. ${ }^{6}$ 
13 | Castiglioni CM, Cremonese L, Prates LA, Schimith MD, Sehnem GD, Wilhelm LA

As ações e orientações realizadas pelo enfermeiro às puérperas precisam contemplar as particularidades do período que é dotado por mudanças físicas, sociais e emocionais, os devidos cuidados com a higiene, alimentação, aleitamento materno, suplementação de ferro, planejamento reprodutivo, complicações no pós-parto, retorno à consulta de rotina e também quanto aos cuidados ligados às condições de saúde, crescimento e desenvolvimento da criança. ${ }^{13}$ Entretanto, também se faz necessário a oferta de espaço para que as mulheres possam expressar suas necessidades específicas de saúde explanando inquietações e angústias, uma vez que essa é considerada uma carência no atendimento e pode representar um diferencial na assistência. ${ }^{3}$

A amamentação, que representa um dos temas mais explanados no pós-parto, precisa englobar orientações que envolvem desde a estimulação da mama até o aparecimento de possíveis intercorrências mamárias. ${ }^{18}$ Sendo assim, ressalta-se que o apoio às mulheres que desejam amamentar precisa começar desde o pré-natal, para que a vivência dessa fase transcorra de maneira positiva posteriormente, uma vez que a compreensão da mãe acerca dos benefícios dessa prática e também a preparação para as dificuldades que podem ser apresentadas fortalecem sua manutenção. ${ }^{20}$

Ao que se refere à relação sexual, ressalta-se que não existe um período específico para a retomada pela mulher, podendo acontecer quando estiver com sua intimidade restaurada e sentir-se preparada, sendo fundamental o apoio do parceiro. ${ }^{21-22}$ A equipe de saúde tem papel fundamental no esclarecimento de dúvidas sobre a sexualidade e a prática sexual, realizando orientações acerca da vivência desse processo e também abordando as questões que envolvem o planejamento reprodutivo e os métodos contraceptivos. ${ }^{17}$

Após o nascimento da criança, a mulher pode vivenciar situações desestruturantes em seu novo cotidiano, e o déficit de conhecimento sobre o momento, somado à sobrecarga diária de afazeres domésticos e a dependência do RN por cuidados, pode levá-la a um sofrimento psíquico. ${ }^{23}$ Nesse contexto, um estudo australiano apontou a importância de investimentos 
Práticas de cuidado no puerpério desenvolvidas por enfermeiras em Estratégias de... | 14

clínicos e de saúde pública no estabelecimento de um forte vínculo entre mãe e filho no período pós-parto precoce como medida de prevenção de estresse pós-parto e depressão. ${ }^{24}$

Os profissionais da saúde, que atuam no cuidado das puérperas e seus familiares, precisam identificar a instabilidade e/ou labilidade emocional, direcionando ações de cuidado que ajudem a família a enfrentar e superar as dificuldades desse momento de transição do ciclo vital. A falta de apoio e orientações durante o puerpério podem comprometer as práticas de cuidado à puérpera, oferecendo riscos potenciais a sua saúde. ${ }^{14}$

Durante a realização da consulta puerperal, o MS preconiza que sejam verificados, no cartão da gestante e/ou por meio de questionamento à puérpera, os dados referentes ao processo gravídico-puerperal como forma de qualificar as práticas de cuidado à puérpera. ${ }^{9}$ Para isso, é preciso saber sobre as condições da gestação, do atendimento ao parto e ao RN, a data do parto, a via de nascimento e sua indicação, intercorrências na gestação, no parto ou no pós-parto, aconselhamentos recebidos, testagem para sífilis e vírus da imunodeficiência humana (HIV) durante a gestação e/ou parto e o uso de medicações. ${ }^{9}$

O planejamento durante a assistência puerperal reflete em um cuidado que atende às necessidades da puérpera e do RN e contribui com a vivência de um puerpério sadio para a nova mãe. ${ }^{25}$ Nesse sentido, vale ressaltar que a família também apresenta papel importante no suporte e apoio à mulher e às demandas do RN. Logo, deve ser orientada desde o pré-natal sobre sua responsabilidade enquanto rede de apoio, ${ }^{23}$ incluindo o pai na nova rotina de cuidados exigida pelo período. ${ }^{1}$

O puerpério pode ser um momento na vida mulher em que a felicidade de se tornar mãe difunde-se com os diversos sentimentos e alterações fisiológicas, que quando se desviam de seu percurso natural podem comprometer a saúde das mulheres. Assim, é essencial que os enfermeiros, principais responsáveis por esse cuidado na APS, compreendam o significado desse período, as necessidades femininas emergentes nessa fase e a importância de práticas de 
15 | Castiglioni CM, Cremonese L, Prates LA, Schimith MD, Sehnem GD, Wilhelm LA

cuidado qualificadas e desenvolvidas a partir de uma abordagem integral, para que assim modifiquem seus métodos e realizem uma assistência puerperal que identifique e previna possíveis intercorrências e que realmente contribua no exercício da maternidade e na saúde da mãe e da criança.

\section{Conclusão}

As enfermeiras percebem o puerpério como um período de adaptações, mudanças e transformações fisiológicas e hormonais que podem sofrer intercorrências. Ademais, também compreendem que, no decorrer desse processo, as mulheres ficam mais sensibilizadas e vulneráveis, pois vivenciam uma nova fase que é permeada por dúvidas que causam labilidade emocional, principalmente quando primigestas.

Infere-se que as enfermeiras desta pesquisa percebem a relevância das práticas de cuidado no puerpério e suas principais características uma vez que reconhecem as alterações hormonais, emocionais e sociais do período e a importância da atuação dos profissionais nessa fase ao compreendê-la cercada por transformações, adaptações e vulnerabilidade. Além disso, a maioria consegue destacar as necessidades e os principais pontos a serem trabalhados e enfatizados nesse processo. Embora algumas profissionais realizem um cuidado mais objetivo do que as outras e o empenho para que a consulta puerperal realmente aconteça seja diferente em cada local, percebe-se que o cuidado no puerpério está acontecendo de acordo com o preconizado pelo MS.

No entanto, ressalta-se que o município estudado possui baixa cobertura de ESF, o que pode representar uma limitação para esta pesquisa, visto que nessa circunstância muitas puérperas podem estar sendo assistidas de modo diferente ao apresentado, não sendo possível conhecer o cuidado prestado durante o puerpério em toda a APS. 
Práticas de cuidado no puerpério desenvolvidas por enfermeiras em Estratégias de... | 16

\section{Referências}

1. Dassoler MF, Ceretta LB, Soratto MT. Desafios enfrentados pelo enfermeiro na consulta puerperal. Rev Interdiscip Estud Saúde [Internet]. 2017 [acesso em 2020 abr 21];6(2):162-76. Disponível em: http://periodicos.uniarp.edu.br/index.php/ries/article/view/840

2. Mazzo MHSN, Brito RS. Nursing instrument to attend mothers who recently gave birth in primary health care. Rev Bras Enferm. 2016 Mar-Apr;69(2):294-303. doi: https://doi.org/10.1590/00347167.2016690215I

3. Corrêa MSM, Feliciano KVO, Pedrosa EM, Souza AI. Acolhimento no cuidado à saúde da mulher no puerpério. Cad Saúde Pública. 2017 Apr;33(3):e00136215. doi: http://dx.doi.org/10.1590/0102-311x00136215

4. Strefling ISS, Borba CB, Soares MCSC, Demori CC, Vaz CHGJ, Santos CP. Percepções de puérperas sobre o cuidado de enfermagem no alojamento conjunto. Rev Pesq Cuid Fundam. 2017 Apr-Jun;9(2):3339. doi: http://dx.doi.org/10.9789/2175-5361.2017.v9i2.333-339

5. Andrade RD, Santos JS, Maia MAC, Mello DF. Factors related to women's health in puerperium and repercussions on child health. Esc Anna Nery Rev Enferm [Internet]. 2015 Jan-Mar [cited 2019 Feb 15];19(1):181-6. Available from: https:/www.scielo.br/scielo.php?script=sci_arttext\&pid=S1414$81452015000100181 \& \operatorname{lng}=\mathrm{es} \& \mathrm{nrm}=1 \& \ln \mathrm{l}=\mathrm{en}$

6. Baratieri T, Natal S. Ações do programa de puerpério na atenção primária: uma revisão integrativa. Ciênc Saúde Colet [Internet]. 2019 [cited 2020 Apr 21];24(11):4227-38. Available from: http://www.cienciaesaudecoletiva.com.br/artigos/acoes-do-programa-de-puerperio-na-atencao-primariauma-revisao-integrativa/16743? id=16743

7. Mori E, Iwata H, Sakajo A, Maehara K, Tamakoshi K. Association between physical and depressive symptoms duringthe first 6 months postpartum. Int J Nurs Pract. 2017 Jun;23(1):12545. doi: https://doi.org/10.1111/ijn.12545

8. Vargas GS, Alves VH, Rodrigues DP, Branco MBLR, Souza RMP, Guerra JVV. Atuação dos profissionais de saúde da estratégia saúde da família: promoção da prática do aleitamento materno. Rev Baiana Enferm. 2016;30(2):1-9. doi: http://dx.doi.org/10.18471/rbe.v30i2.14848

9. Ministério da Saúde (BR). Protocolos da Atenção Básica: saúde das mulheres. Brasília (DF): Ministério da Saúde; 2016.

10. Collaço VS, Santos EKA, Souza KV, Alves HV, Zampieri MF, Gregório VRP. O significado atribuído pelo casal ao parto domiciliar planejado, assistido pelas enfermeiras obstétricas da equipe HANAMI. Texto \& Contexto Enferm. 2017 Jun;26(2):e6030015. doi: http://dx.doi.org/10.1590/0104-07072017006030015

11. Medeiros LS, Costa ACM. Período puerperal: a importância da visita domiciliar para enfermeiros da Atenção Primária à Saúde. Rev Rene (Online). 2016 Jan-Fev;17(1):112-9. doi: 
http://dx.doi.org/10.15253/2175-6783.2016000100015

12. Minayo MCS. O desafio do conhecimento: pesquisa qualitativa em saúde. $14^{a}$ ed. São Paulo (SP): Hucitec-Abrasco; 2014.

13. Luz VLES, Sales JCS, Siqueira MLS, Vieira, TS, Coêlho DM, Barbosa MG. Assistência do enfermeiro da Estratégia Saúde da Família na visita domiciliar à puérpera. Rev Interdiscip [Internet]. 2016 Fev-Mar [acesso em 2019 Fev 18];9(1):13-23. Disponível em: http://revistainterdisciplinar.uninovafapi.edu.br/index.php/revinter/article/viewFile/552/pdf_280

14. Cassiano AN, Araújo MG, Holanda CSM, Costa RKS. Perception of nurses on humanization in nursing care in immediate puerperium. Rev Pesq Cuid Fundam. 2015 Jan-Mar;7(1):2051-60. doi: https://doi.org/10.9789/2175-5361.2015.v7i1.2051-2060

15. Santos KSS, Paixão GPN, Brito PMC, Jerônimo AS, Oliveira EHSA. A experiência de mulheres no pós-parto sobre o planejamento familiar. Saude Pesqui (Online). 2019 Jan-Apr [acesso em 2020 Mar 01];12(1):177-85. doi: https://doi.org/10.17765/2176-9206.2019v12n1p177-185

16. Figueiredo JV, Fialho AVM, Mendonça GMM, Rodrigues DP, Silva LF. A dor no puerpério imediato: contribuição do cuidado de enfermagem. Rev Bras Enferm. 2018 Sept;71(Suppl 3):1424-31. doi: http://dx.doi.org/10.1590/0034-7167-2017-0345

17. Prigol AP, Baruffi LM. O papel do enfermeiro no cuidado à puérpera. Rev Enferm UFSM. 2017 JanFeb;7(1):1-8. doi: http://dx.doi.org/10.5902/2179769222286

18. Dantas SLC, Rodrigues DP, Fialho AVM, Barbosa EMG, Pereira AMM, Mesquita NS. Representações sociais de enfermeiros da atenção primária à saúde sobre cuidado de enfermagem no pós-parto. Cogitare Enferm. 2018 Apr;(23)3:e53250. doi: http://dx.doi.org/10.5380/ce.v23i3.53250

19. Correia TIG, Pereira MLI. Os cuidados de enfermagem e a satisfação dos consumidores no puerpério. Rev Eletrônica Enferm. 2015 Jan-Mar;17(1):21-9. doi: http://dx.doi.org/10.5216/ree.v17i1.28695

20. Hashin, T. H. et al. Predictors of appropriate breastfeeding knowledge among pregnant women in Moshi Urban, Tanzania: a cross-sectional study. Int Breastfeeding J. 2016 Feb;12(11). doi: https://doi.org/10.1186/s13006-017-0102-4

21. Romagnolo AN, Costa AO, Souza NL, Somera VCO, Gomes MB. A família como fator de risco e de proteção na gestação, parto e pós-parto. Semin Ciênc Soc Hum. 2017 Jul-Dez;38(2):133-46. doi: https://doi.org/10.5433/1679-0383.2017v38n2p133

22. Schlagintweit HE, Bailey K, Rosen NO. A new baby in the bedroom: frequency and severity of postpartum sexual concerns and their associations with relationship satisfaction in new parent couples. J Sex Med. 2016;13(10):1455-65. doi: https://doi.org/10.1016/j.jsxm.2016.08.006 
23. Mazzo MHSN, Brito RS, Silva ICG, Feitosa MM, Lima MSE, Silva ECP. Percepção das puérperas sobre seu período pós-parto. Investig Enferm. 2018;20(2):1-9. doi: https://doi.org/10.11144/Javeriana.ie202.ppsp

24. Rossen L, Mattick RP, Wilson J, Clare PJ, Burns L, Allsop S, et al. Mother-infant bonding and emotional availability at 12-months of age: the role of early postnatal bonding, maternal substance use and mental health. Matern Child Health J. 2019;23(12):1686-98. doi: https://doi.org/10.1007/s10995-01902809-1

25. Andrade CJ, Bacceli MS, Benincasa $\mathrm{M}$. O vínculo mãe-bebê no período de puerpério: uma análise Winnicottiana. Vínculo [Internet]. 2017 [acesso em 2019 fev 18];14(1):1-13. Disponível em: pepsic.bvsalud.org/pdf/vinculo/v14n1/v14n1a04.pdf

\section{Autor correspondente}

Nome: Críslen Malavolta Castiglioni

E-mail: crislen_castiglioni@hotmail.com

Endreço: Rua Neri Gomes Peixoto, 1700. Edifício Maranata, ap 203, centro. Santiago/RS.

CEP: 97700-000

\section{Contribuições de Autoria}

\section{1 - Críslen Malavolta Castiglioni}

Planejamento do projeto da pesquisa, obtenção, análise e interpretação dos dados e redação do manuscrito e revisão crítica.

\section{2 - Luiza Cremonese}

Análise e interpretação dos dados e redação do manuscrito.

\section{3 - Lisie Alende Prates}

Análise e interpretação dos dados e redação do manuscrito.

4 - Maria Denise Schimith

Redação do manuscrito e revisão crítica.

\section{5 - Graciela Dutra Sehnem}

Redação do manuscrito e revisão crítica.

\section{6 - Laís Antunes Wilhelm}

Planejamento do projeto da pesquisa, obtenção, análise e interpretação dos dados e redação do manuscrito e revisão crítica. 
19 | Castiglioni CM, Cremonese L, Prates LA, Schimith MD, Sehnem GD, Wilhelm LA

\section{Como citar este artigo}

Castiglioni CM, Cremonese L, Prates LA, Schimith MD, Sehnem GD, Wilhelm LA. Práticas de cuidado no puerpério desenvolvidas por enfermeiras em Estratégias de Saúde da Família. Rev. Enferm. UFSM. 2020 [Acesso em: Anos Mês Dia]; vol.10 e50: 1-19. DOI:https://doi.org/10.5902/2179769237087 